> Parliament, non-Arctic nations and non-governmental organizations. Local governments and peoples in turn strongly object to attempts by outsiders to impose controls. The European Parliament's 2008 resolution on Arctic governance, which, inspired by the Antarctic Treaty, called for an international treaty to protect the Arctic, combined with the 2009 ban on seal products among other items, was so provocative, that the European Union's request to be an observer on the Arctic Council - the eight nations with territory in the Arctic - has repeatedly been put on hold. Many conservation organizations, such as Greenpeace and Sea Shepherd, and animal-welfare organizations, receive little support across the Arctic, whereas those that strongly encourage local dialogue, including the WWF, are more welcomed.

Academic institutions are working with governments, companies and other institutions to boost economic growth in the Arctic. Cooperation between the private sector, the University of Oulu and local government in Oulu, Finland, fostered the growth of the Finnish mobile-phone company Nokia. Likewise, universities in Tromsø, Norway, and Fairbanks, Alaska, are drivers of knowledgebased development; as are two new institutions in northern Russia: the Northern Arctic Federal University in Arkhangelsk and the North-Eastern Federal University in Yakutsk.
The University of the Arctic was started in 2001 as a network of collaborating highereducation institutions, supported by the member states of the Arctic Council and the Arctic indigenous peoples. Today it links 138 universities and colleges across Russia, North America and the Nordic countries, ranging from small institutions with 100 students to major research-intensive universities with tens of thousands of students. The network shares research initiatives and joint-study programmes, and helps to opti-

"Localpeoples
strongly object
to attempts
by outsiders
to impose
controls."
mize use of limited resources. It is often argued that a critical mass of people and jobs in one location is necessary to create a viable economy in today's world. The University of the Arctic proves that a dispersed network can be just as successful.

Another important role of academia is as the place where research questions are formulated and tackled. The International Arctic Science Committee, the University of the Arctic and the International Arctic Social Sciences Association have agreed to jointly organize the third International Conference on Arctic Research Planning in 2015. This is a bottom-up, scientist-driven initiative carried out every ten years to identify major research questions important in the north. This time, we intend to include more contributions from local peoples. Their concerns are often different from those of academics: with climate change, for example, their focus is on building the knowledge necessary to deal with its effects, rather than on revealing more details of the processes behind it. Local peoples seek ways to merge traditional and academic knowledge to help develop insights that might, for example, be relevant to fishermen when fish migration patterns change, or to reindeer herders when grass and snow conditions alter, as well as replacing soot-producing fossil energy with renewable options.

It is only when the whole population of the Arctic has a say in developing knowledge in and about the region that we will be equipped with the tools to define our own future and decide at what pace our resources will be developed. It is crucial that academics, through facilities such as the University of the Arctic, become involved with those deliberations, so that the right scientific data are made available for policy-makers. Working together, we can strive towards a green economy in the north.

Lars Kullerud is president of the University of the Arctic, and is based at UNEP/GRIDArendal, N-4836 Arendal, Norway. e-mail:lars.kullerud@uarctic.org

\title{
A peaceful Arctic
}

\section{Encourage dialogue between the producers and consumers of scientific knowledge in the north to keep the region conflict free, says Oran R. Young.}

\begin{abstract}
A cocktail of powerful forces, including the onset of climate change, the globalization of economic relationships and the shifting distribution of power in international society, is transforming the Arctic. Once regarded as a remote region of interest largely to explorers, missionaries and anthropologists, the Arctic has become a focus of attention for captains of industry and global policy-makers.

Conditions in the far north are very different from those at the opposite side of the globe. There, the highly effective Antarctic Treaty System relies on the scientific community to help administer the internationally agreed provisions for jurisdiction, demilitarization, environmental protection and the prohibition of mineral development in the Antarctic. There are no direct counterparts to this role in the Arctic, a region that is home to millions of human residents, subject to the undisputed sovereignty of its coastal
\end{abstract}

states, a theatre of operations for nuclearpowered icebreakers and naval vessels, and a site of world-class industrial activities including mining.

Journalists and pundits have broadcast dramatic scenarios that feature a scramble for the Arctic's resources, leading inexorably to resource wars and armed clashes. These concerns are misplaced. In reality, the eight Arctic states have settled most disputes over boundaries and the use of the region's resources through cooperative measures; they have also created the Arctic Council, a body that provides a forum for addressing emerging issues in an orderly manner.

Scientists have long played a part in these peaceful interactions in the Arctic, and they

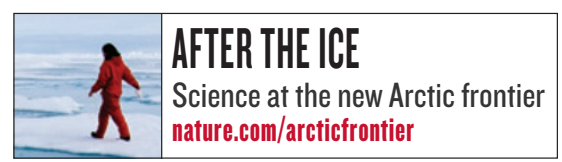

will continue to do so. But steps can and should be taken to increase the relevance of science to emerging policy concerns, to improve the transfer of scientific knowledge and expertise into the hands of policy-makers, and to ensure that the Arctic remains a zone of peace.

\section{BREAKING THE ICE}

In 1987, Mikhail Gorbachev, then president of the Soviet Union, gave his 'Arctic zone of peace' speech, in which he called for a series of concrete measures to overcome East-West divisions in the area, including arms control measures and cooperative resource development. Gorbachev explicitly addressed the role of scientists in achieving that goal, and in the wake of his speech, science became an important vehicle for communication between the two camps. This led to the establishment in 1990 of the International Arctic Science Committee 


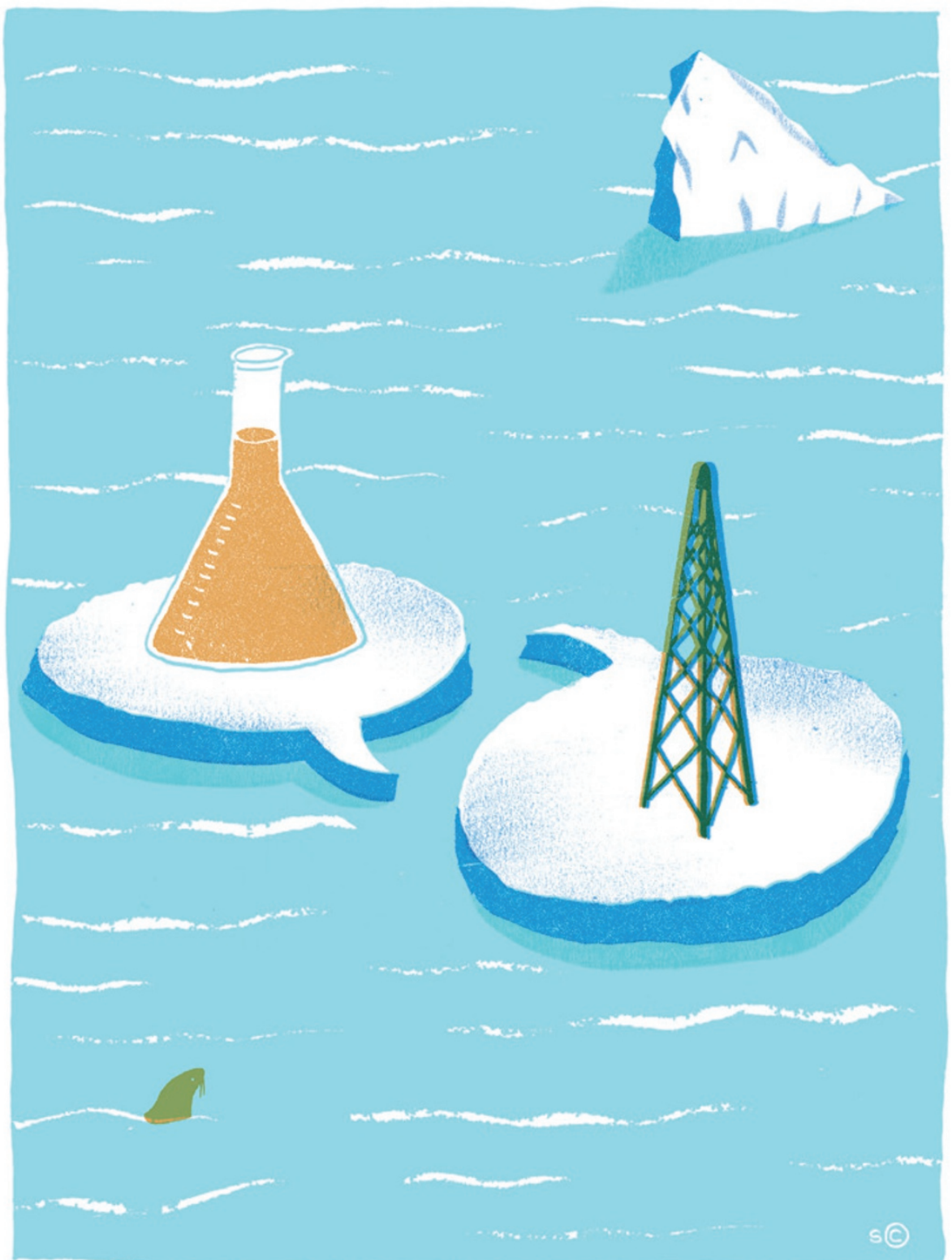

(IASC) - a non-governmental group of national scientific organizations aimed at promoting cooperation.

Once the ice was broken, the Arctic states (Canada, Russia, the United States and the five Nordic countries) rapidly formed the Arctic Environmental Protection Strategy, in 1991, and its successor, the Arctic Council, in 1996. The most striking achievement of these bodies is the production and dissemination of a set of influential, sciencerich reports, including The State of the Arctic Environment (1997), Arctic Human Development Report (2004), Arctic Climate Impact Assessment (2004) and Arctic Marine Shipping Assessment. The first report's evidence of pollutants in the pristine northern environment acted as a catalyst for the 2001 Stockholm Convention on Persistent Organic Pollutants.

Science continues to contribute to effective governance of the Arctic. First, it provides an idiom for addressing contentious issues. Take, for example, the delimitation of Arctic coastal state jurisdiction over the seabed beyond the Exclusive Economic Zones. These states have rights to areas that are shown to be natural extensions of their continental shelves (see pages 172 and 174). Canada, Denmark and the United States have joined forces to conduct the mapping research needed to present evidence to the United Nations Commission on the Limits of the Continental Shelf. Russian policymakers have expressed a clear desire for scientific cooperation in resolving any jurisdictional disagreements.

Second, science helps to identify emerging issues and provide the evidence needed to move them towards the top of the policy agenda. A recent example involves the discovery of the prominent role of short-lived climate forcers, such as atmospheric soot ('black carbon'). The scientific documentation of this problem prompted the Arctic Council to create a task force on the topic in 2009, leading to a 2011 Arctic Council decision to organize demonstration projects (for example on fire prevention) to help reduce emissions.

A third role for science is to provide a reality check for commercial ventures: researchers can amass evidence to assess the credibility of forecasts of oil and gas reserves in the Arctic, the possible obstacles to commercial shipping, and the requirements for managing commercial fisheries.

\section{POLE TO POLE}

Despite the differences between the north and south poles, northerners can learn from the Antarctic experience, notably the strong, institutionalized links between the producers of scientific knowledge and the guardians of the region's governance system.

The Scientific Committee on Antarctic Research (SCAR) is a non-governmental body operating as a committee of the International Council for Science (ICSU). It includes the national research councils and scientific academies of countries involved in Antarctic research, and its services are relied on by the Antarctic Treaty Consultative Meetings - the annual meetings of the governments of the treaty states. SCAR also collaborates with the Committee for Environmental Protection, the expert body that advises the politicians on environmental policy in the Antarctic. In the Arctic, the IASC has a comparable role to that of SCAR. But it is neither a committee of ICSU nor an explicitly acknowledged contributor to the work of the Arctic Council. This makes for a tenuous connection between the producers and the consumers of Arctic science. Communication between the two groups is complicated, and is hampering the development of mutual respect and trust.

Such problems almost torpedoed the production of a policy document summarizing the key findings of the Arctic Climate Impact Assessment for consideration at the 2004 Arctic Council ministerial meeting. The absence of a well-defined and mutually understood procedure benefited no one.

The IASC and the Arctic Council must, and will, remain separate, each with its own mandate, membership and operating procedures. But they need an explicit agreement on 'rules of engagement' that encourage communication. The next Arctic Council ministerial meeting in 2013 should adopt a memorandum of agreement covering this relationship.

Oran R. Young is at the Bren School of Environmental Science and Management, University of California, Santa Barbara, Santa Barbara, California 93106, USA. e-mail:oran.young@gmail.com 